Article

\title{
The Profile of Urinary Headspace Volatile Organic Compounds After 12-Week Intake of Oligofructose-Enriched Inulin by Children and Adolescents with Celiac Disease on a Gluten-Free Diet: Results of a Pilot, Randomized, Placebo-Controlled Clinical Trial
}

\author{
Natalia Drabińska ${ }^{1, *} \mathbb{\infty}$, Elżbieta Jarocka-Cyrta ${ }^{2}{ }^{\oplus}$, Norman Mark Ratcliffe ${ }^{3}$ and \\ Urszula Krupa-Kozak 1,*(D) \\ 1 Department of Chemistry and Biodynamics of Food, Institute of Animal Reproduction and Food Research of \\ Polish Academy of Sciences, Tuwima 10 Str., 10-748 Olsztyn, Poland \\ 2 Department of Pediatrics, Gastroenterology, and Nutrition, Collegium Medicum, University of Warmia \& \\ Mazury, Oczapowskiego 2 Str., 10-719 Olsztyn, Poland; ejarocka@op.pl \\ 3 Institute of Biosensor Technology, the University of the West of England, University of the West of England, \\ Coldharbour Lane, Frenchay, Bristol BS16 1QY, UK; norman.ratcliffe@uwe.ac.uk \\ * Correspondence: n.drabinska@pan.olsztyn.pl or natalia_drabinska@wp.pl (N.D.); \\ u.krupa-kozak@pan.olsztyn.pl (U.K.-K.); Tel.: +48-895-234-639 (N.D); +48-895-234-618 (U.K.-K.)
}

Academic Editor: Derek J. McPhee

Received: 20 March 2019; Accepted: 4 April 2019; Published: 5 April 2019

check for updates

\begin{abstract}
The concentration of volatile organic compounds (VOCs) can inform about the metabolic condition of the body. In the small intestine of untreated persons with celiac disease (CD), chronic inflammation can occur, leading to nutritional deficiencies, and consequently to functional impairments of the whole body. Metabolomic studies showed differences in the profile of VOCs in biological fluids of patients with $\mathrm{CD}$ in comparison to healthy persons; however, there is scarce quantitative and nutritional intervention information. The aim of this study was to evaluate the effect of the supplementation of a gluten-free diet (GFD) with prebiotic oligofructose-enriched inulin (Synergy 1) on the concentration of VOCs in the urine of children and adolescents with CD. Twenty-three participants were randomized to the group receiving Synergy 1 ( $10 \mathrm{~g}$ per day) or placebo for 12 weeks. Urinary VOCs were analyzed using solid-phase microextraction and gas chromatography-mass spectrometry. Sixteen compounds were identified and quantified in urine samples. The supplementation of GFD with Synergy 1 resulted in an average concentration drop $(36 \%)$ of benzaldehyde in urine samples. In summary, Synergy 1, applied as a supplement of GFD for 12 weeks had a moderate impact on the VOC concentrations in the urine of children with CD.
\end{abstract}

Keywords: volatile organic compounds; celiac disease; gluten-free diet; gas chromatography-mass spectrometry; solid-phase microextraction; prebiotic

\section{Introduction}

Volatile organic compounds (VOCs) are carbon-based molecules that are volatile at ambient temperature [1]. Hundreds of VOCs are secreted by cells of the human body, as a result of metabolic processes. The qualitative and quantitative profile of VOCs in biological fluids can vary depending on the metabolic changes; therefore, the pattern of volatile metabolites may reflect the presence of disease [2]. Several studies showed an association between the pattern of volatile biomarkers 
and the presence of gastrointestinal diseases [3-9]. Gas chromatography coupled with mass spectrometry (GC-MS), a "gold standard" in VOC analysis, was applied to distinguish patients with diarrhea-predominant irritable bowel syndrome, Crohn's disease, ulcerative colitis, and healthy controls [8], as well as celiac disease (CD) and irritable bowel syndrome [6]. Moreover, the effect of a gluten-free diet (GFD) on the exhaled breath was evaluated $[10,11]$. The great success of previous studies contributed to the tremendous progress in the development of new analytical techniques for VOC detection, such as field-asymmetric ion mobility spectrometry and selected ion flow tube mass spectrometry, successfully applied in the analysis of VOCs in gastrointestinal diseases [5,12]. Recently, volatolomics was established as a new scientific domain with significant diagnostic potential [13]. The application of the VOC analysis can be an innovative and non-invasive tool for the diagnosis of diseases, as well as for the monitoring of the effectiveness of treatment [14].

It is believed that changes in VOCs observed in gastrointestinal diseases are the result of the impaired fermentation activity of the gut microbiota [6]. In many clinical trials, the changes in the metabolism of bacteria were suggested as more informative than the microbiota composition itself [15-17]. Moreover, many of the nutritional interventions had moderate or no effect on qualitative and/or quantitative changes of intestinal microbiota; however, they had a much more prominent effect on their metabolism $[14,16,17]$. In the intestines, the interaction between commensal bacteria, human cells, and pathogens occurs and results in the formation of hundreds of VOCs observed in feces, urine, sweat, blood, and exhaled breath [18]. The presence of intestinal VOCs in urine, sweat, blood, and breath can be related to changes in the intestinal barrier [6], which are attributed to several gastrointestinal diseases $[19,20]$. The analysis of VOCs in urine has several benefits over the other biological fluids. Urine collection is non-invasive and does not cause discomfort even with multiple sampling. Moreover, the concentration of VOCs in urine is higher compared to blood, as urine is pre-concentrated in the kidney, which facilitates the detection of metabolites [21]. However, on the other hand, the pre-concentration of urine can vary within and between individuals, which should be considered as a confounding factor.

$\mathrm{CD}$ is a life-long gluten-related enteropathy observed in genetically predisposed individuals. The prevalence of $C D$ is estimated for approximately $1 \%$ of the global population; however, it is suggested that many patients remain undiagnosed [22]. In addition to the intestinal (abdominal pain, diarrhea) and extra-intestinal (increased bone fractures, anemia, depression) symptoms, the dysbiosis of intestinal microbiota, characterized by lower diversity and disproportion between Gram-positive and Gram-negative bacteria [23], as well as altered intestinal permeability [20], is commonly observed in CD patients. The only approved treatment of CD is a GFD. However, in many patients, even after long-term adherence to the treatment, nutritional deficiencies and a lack of intestinal recovery are observed [24-26]. Therefore, there is a strong need to incorporate auxiliary therapies, including GFD supplementation, into the treatment regime of the $C D$, followed by an evaluation of their safety and effects.

Prebiotics, defined as substrates that are selectively utilized by host microorganisms conferring a health benefit [27], were reported to increase the absorption of nutrients [28] and to improve the histomorphological parameters of intestines [29], confirmed in a clinical trial and in vivo studies. Recently, the beneficial effects of prebiotics on several aspects of health in CD patients were reported [17,30-32]. Briefly, prebiotics were found to stimulate the activity of the intestinal microbiota [17], modulate the amino-acid metabolism [30], improve the fat-soluble vitamin status [31], and improve bone metabolism [32]. However, the impact of GFD supplementation with prebiotics on the VOC pattern remains to be analyzed.

In general, the number of studies evaluating VOC pattern after nutritional interventions is limited. Therefore, this exploratory, randomized, placebo-controlled study is proposed to evaluate the effect of prebiotic oligofructose-enriched inulin intake on the profile of VOCs in the urine of children and adolescents with CD following a GFD, using solid-phase microextraction with GC-MS. 
Hypothesis: Nutritional intervention with oligofructose-enriched inulin will improve the intestinal health of children with CD, affecting the profile of urinary VOC.

\section{Results}

In the urine of patients with $\mathrm{CD}$, a total of sixteen compounds, representing different chemical groups, were identified and quantitatively characterized (Table 1). Additionally, 4-methylphenol and 2-pentylfuran were determined in some urine samples, but values above the limit of quantification were detected only in a few samples. An example of the chromatogram is presented in Figure 1.

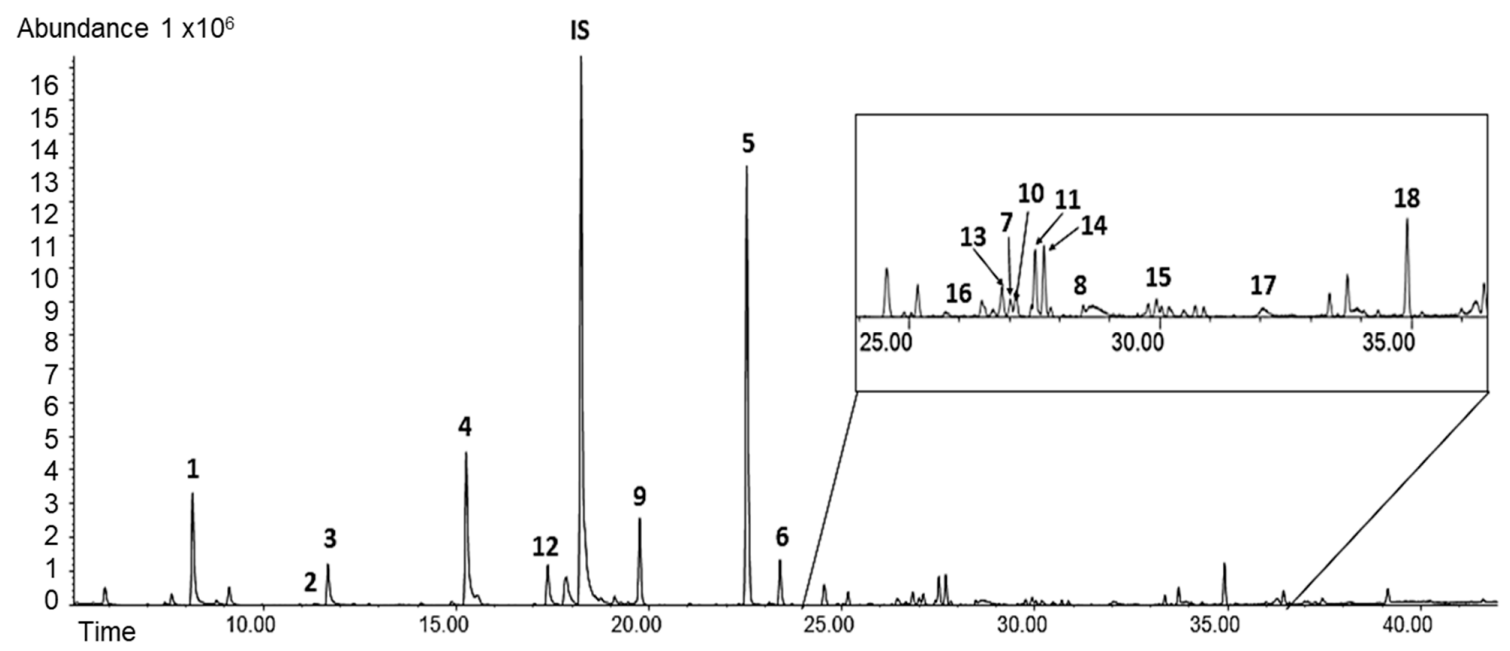

Figure 1. An example of a chromatogram of urinary volatile organic compounds (VOCs) obtained with gas chromatography-mass spectrometry (GC-MS): (1) acetone; (2) butane-2,3-dione; (3) butan-2-one; (4) pentan-2-one; (5) heptan-4-one; (6) heptan-2-one; (7) 6-methylhept-5-en-2-one; (8) trans-3-octen-2-one;

(9) hexanal; (10) benzaldehyde; (11) octanal; (12) dimethyl disulfide; (13) dimethyl trisulfide;

(14) D-limonene; (15) linalool; (16) 2-pentylfuran; (17) 4-methylphenol; (18) 1,3-di-tert-butylbenzene.

At baseline, the concentrations of VOCs in urine were similar in both experimental groups (Table 1). The median concentration of trans-3-octen-2-one was similar in both experimental groups at baseline; however, this ketone was not detected in three urine samples of patients from the Synergy 1 group.

The supplementation of GFD with Synergy 1 did not impact on the profile or the concentration of the majority of VOCs in the urine of CD patients. The only significant $(p<0.05)$ change was observed for benzaldehyde, where the concentration decreased by $36 \%$ after the intervention (Table 1 ). Furthermore, trans-3-octen-2-one was not detected in some urine samples (two from Synergy 1 group and one from the placebo group); however, it had no effect on differences between experimental groups. The decrease in the concentrations of 1,3-di-tert-butylbenzene was observed in the placebo group after the twelve-week intervention.

Multivariate analysis showed a high inter-individual variation of the data (Figure 2). Principal component analysis (PCA) plots explained $46.42 \%$ and $44.25 \%$ of variations at baseline and after the intervention, respectively. No separation was observed either before or after the intervention. At baseline, anthropometric indices (age, height, body weight) had an influence on D-limonene and acetone concentrations. The level of linalool was associated with the time of GFD adherence. Similar associations were not observed after the intervention (Figure 2). 
Table 1. Volatile organic compounds (VOCs) (nmol/L) detected and quantified in the urine of children from Synergy 1 and placebo group, before (T0) and after (T1) the intervention, expressed as median (P25-P75).

\begin{tabular}{|c|c|c|c|c|}
\hline & \multicolumn{2}{|c|}{ T0 } & \multicolumn{2}{|c|}{ T1 } \\
\hline & Placebo & Synergy 1 & Placebo & Synergy 1 \\
\hline \multicolumn{5}{|c|}{ Ketones } \\
\hline acetone & 12023 (9066-17649) & 12184 (10229-17740) & $12816(10549-14704)$ & 12564 (9969-19006) \\
\hline butane-2,3-dione & $66.80(50.50-88.74)$ & $63.22(53.03-104.73)$ & $59.10(28.12-68.74)$ & $53.63(44.46-65.58)$ \\
\hline & & & 168.38 & 229.20 \\
\hline butan-2-one & 167.59 (73.60-229.55) & 180.77 (95.76-271.57) & $(116.26-313.56)$ & $(126.17-294.85)$ \\
\hline pentan-2-one & $21.76(9.42-57.88)$ & $31.80(20.55-54.27)$ & 41.57 (18.19-60.49) & $40.04(32.83-64.30)$ \\
\hline heptan-4-one & $41.91(22.65-125.91)$ & $53.32(28.13-87.32)$ & $86.19(32.29-103.91)$ & $84.02(51.86-130.34)$ \\
\hline heptan-2-one & $6.94(3.42-14.82)$ & $6.11(2.59-17.55)$ & $10.31(3.39-12.98)$ & $8.04(5.38-11.73)$ \\
\hline 6-methylhept-5-en-2-one & $1.31(0.57-4.08)$ & $1.33(0.50-2.30)$ & $1.87(0.38-2.68)$ & $1.33(0.52-1.83)$ \\
\hline trans-3-octen-2-one & $0.59(0.39-4.49)$ & $0.56(0.41-0.92)$ & $1.08(0.46-1.90)$ & $0.71(0.39-1.02)$ \\
\hline \multicolumn{5}{|c|}{ Aldehydes } \\
\hline hexanal & $37.38(24.60-59.95)$ & $23.79(17.99-36.84)$ & $36.59(24.22-45.63)$ & $28.27(18.84-38.78)$ \\
\hline benzaldehyde & $7.14(3.14-22.86)$ & $7.16(3.47-12.94)$ & $7.53(2.48-10.00)$ & $6.21(3.52-7.14)^{a}$ \\
\hline octanal & $0.83(0.35-4.11)$ & $0.62(0.15-2.58)$ & $0.85(0.20-2.04)$ & $1.11(0.39-1.34)$ \\
\hline \multicolumn{5}{|c|}{ Sulfur compounds } \\
\hline dimethyl disulfide & $19.29(11.39-23.26)$ & $13.02(6.86-18.44)$ & $8.94(6.70-15.16)$ & $12.67(7.02-19.29)$ \\
\hline dimethyl trisulfide & $1.22(0.95-3.30)$ & $1.01(0.34-2.27)$ & $1.28(0.46-1.90)$ & $1.72(0.50-3.09)$ \\
\hline \multicolumn{5}{|c|}{ Terpenes } \\
\hline limonene & $45.27(9.29-67.86)$ & $32.56(4.02-42.40)$ & $36.78(24.22-45.63)$ & $28.79(5.46-62.43)$ \\
\hline linalool & $20.63(14.68-28.12)$ & $19.28(15.99-29.20)$ & $16.14(11.86-26.20)$ & $18.09(11.76-26.24)$ \\
\hline \multicolumn{5}{|c|}{ Aromatic compounds } \\
\hline 1,3-di-tert-butylbenzene & $0.82(0.42-1.25)$ & $0.52(0.33-0.92)$ & $0.66(0.34-0.87)^{a}$ & $0.57(0.33-0.91)$ \\
\hline
\end{tabular}

a-statistically significant differences within groups before and after the intervention.

\section{Discussion}

Our study, for the first time, reports the profile and concentrations of VOCs in the headspace above the urine of children and adolescents with CD after a 12-week nutritional intervention with prebiotics applied as a supplement of GFD.

Sixteen compounds quantified in the present study were selected based on the previous studies reporting differences in urinary VOCs between healthy children and children with CD $[4,33]$. We hypothesized that, after the nutritional intervention with prebiotics, the urinary profile of VOC in children with CD would be altered, as a consequence of the changes in the gut caused by prebiotics. The present study indicated, however, that applied nutritional intervention did not have a strong effect on the profile of VOCs in urine. The only difference observed after the Synergy 1 intake was a significant reduction in benzaldehyde concentration. The explanation for the benzaldehyde drop in concentration can be related to the microbiota activity. Benzaldehyde can be formed as a result of the conversion of phenylalanine by aminotransferase produced by Lactobacillus bacteria [34]. In our study, the amount of the precursor phenylalanine was similar in both groups before and after the supplementation [30]. However, the Lactobacillus count was significantly lower in the Synergy 1 group as compared to placebo [17]. This might result in a reduction in phenylalanine conversion and, consequently, in decreased benzaldehyde concentration in urine.

In the placebo group, the decrease in the concentration of 1,3-di-tert-butylbenzene was observed. This is particularly interesting because this compound was suggested as a marker of CD, observed only in the urine of children with $C D$, while it existed in none of the samples from healthy children [33]. However, the origin of 1,3-di-tert-butylbenzene in the human body is not clear and requires further studies. It was reported that 1,3-di-tert-butylbenzene is a product of radiolysis of the antioxidant Irgafos used in food packaging [35], and this is a possible explanation of its origin in urine. 
(A)
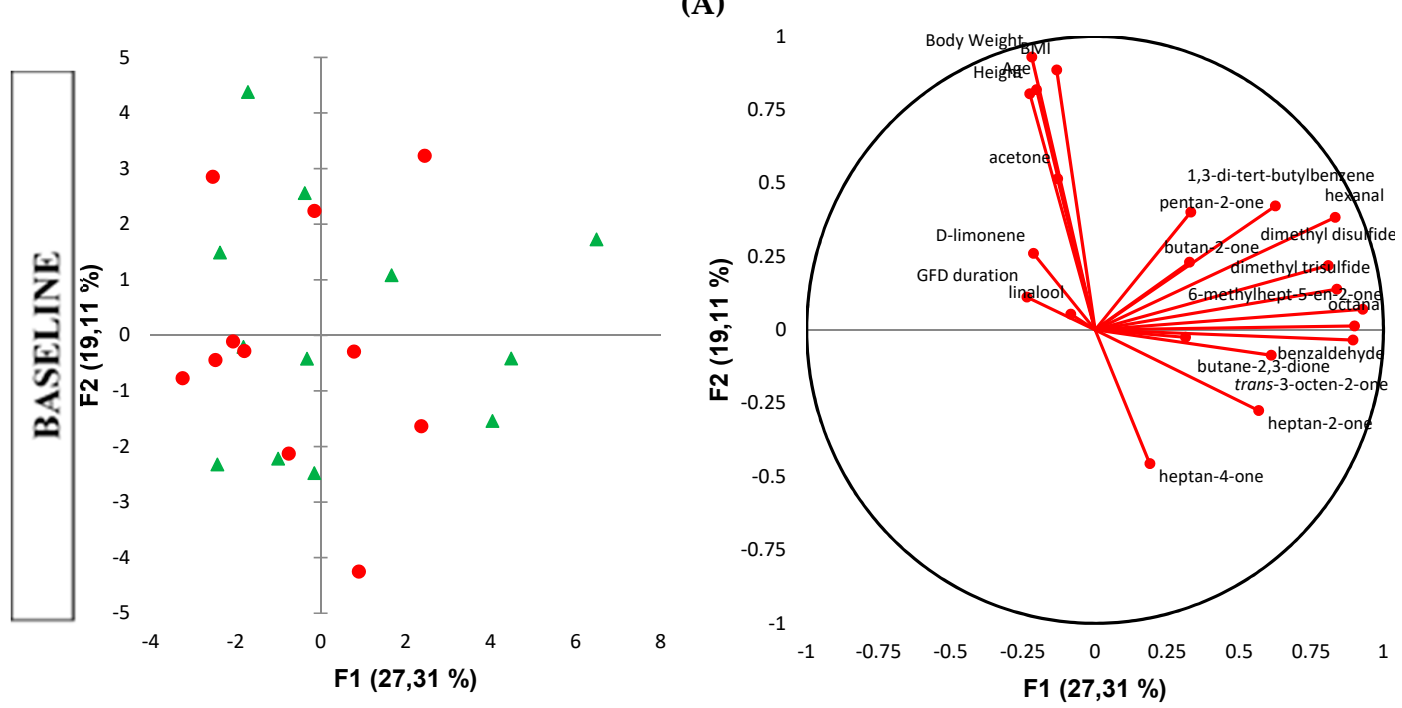

(B)
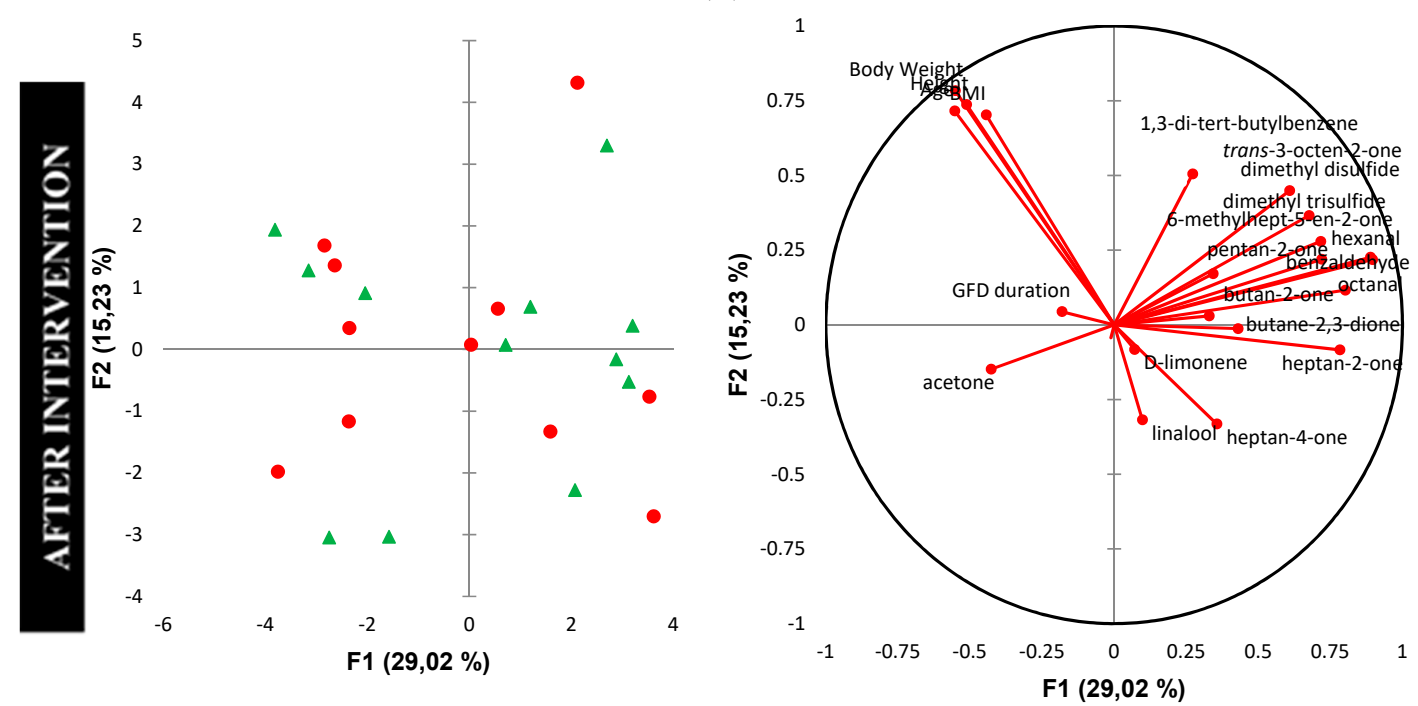

Figure 2. Results of principal component analysis (PCA) of urinary VOCs at baseline (A), and after the intervention (B). Red circles-Synergy 1 group; green triangles-placebo group. Left graphsscore plot; right graphs—correlation circle presenting correlations between individual VOCs and anthropometric indices.

The high inter-individual variation in VOC profiles makes it difficult to demonstrate significant differences after the applied prebiotic intervention. On the other hand, it may result from the recovery of the intestinal mucosa and the reduction in intestine permeability. The recent research suggests that the perturbation in the urinary VOC profile observed in some gastrointestinal diseases may result from changes in the gut barrier [6]. Children and adolescents participating in the present study were treated with a GFD for at least six months (average: $2.9 \pm 1.9$ and $2.3 \pm 1.2$ years in Synergy 1 and placebo group, respectively), which is considered as sufficient time to restore the proper functioning of the intestinal barrier [36]. In literature, the results of the prebiotic supplementation aimed to improve intestinal permeability are inconsistent. Animal studies with non-digestible fructans confirmed beneficial histomorphological changes in the gut and intestinal barrier functioning [29]. Similarly, a randomized, double-blind crossover nutritional intervention study with inulin-enriched pasta showed modulation of circulating levels of zonulin and glucagon-like peptide 2 in healthy young volunteers, suggesting that prebiotics could be used in the prevention of gastrointestinal 
diseases [37]. On the other hand, many clinical trials found no effect of prebiotics on intestinal barrier functions [38-40]. Therefore, the unambiguous impact of prebiotics on intestinal barrier functioning require further in-depth investigation.

To our knowledge, there is only one study analyzing the VOC profiles after nutritional intervention [14], making the discussion of the present results in response to other studies a challenge. The study by Rossi and co-authors [14] referred to irritable bowel syndrome and analyzed VOCs in feces. Although impossible to compare, the results presented in this interesting paper reported that the analysis of VOCs in feces can predict responses to the nutritional intervention. As in the present study, we did not observe profound differences in urinary VOCs after the applied nutritional intervention. In future studies, it would be worthwhile to analyze the VOC profile in feces of children with $\mathrm{CD}$, especially as, in our previous research, we observed significant changes in the concentration of short-chain fatty acids in the feces of children with CD after the intervention with prebiotics [17].

Despite the novel nature of this study, some limitations should be mentioned. Firstly, there was no calculation of the sample size. However, this limitation is related to the pilot type of study. Therefore, the present study should be considered as an exploratory study, providing the data for calculation of the sample size for future validation studies. A second limitation was the small number of participants, causing problems in statistical evaluation based on the high inter-individual variability. This limitation is also strongly associated with the preliminary nature of the study. Thirdly, in this study, the control of the diet was not presented; however, the control of the diet was performed using validated food frequency questionnaires [41], even though details were not presented in this manuscript.

Finally, the study presented here is focused on the targeted analysis of selected compounds, limiting the number of possible responses of a non-analyzed and unknown compound. However, the authors wanted to focus on quantitative analysis, which is missing in the literature; therefore, to calculate accurately, a limited number of compounds had to be selected. However, comparing whole metabolic profiles in the urine of children and adolescents with $\mathrm{CD}$ after the nutritional intervention would also be scientifically interesting; therefore, it is suggested as a future study.

\section{Materials and Methods}

\subsection{Chemicals and Materials}

Chemical standards of acetone, butane-2,3-dione, butan-2-one, thiophene, dimethyl disulfide, hexanal, heptan-4-one, heptan-2-one, 2-pentylfuran, dimethyl trisulfide, 6-methylhept-5-en-2-one, benzaldehyde, octanal, D-limonene, trans-3-octen-2-one, linalool, 4-methylphenol, 1,3-di-tert-butylbenzene, internal standard (4-methylpentan-2-ol), and sodium chloride ( $\mathrm{NaCl}, \geq 99.5 \%$ ) were supplied by Sigma-Aldrich (Saint Louis, MO, USA). MilliQ water (Millipore, Bedford, MO, USA) was used for the preparation of standards. Hydrochloric acid $(\mathrm{HCl}, 37 \%)$ was purchased from Chempur (Piekary Ślaskie, Poland). The 75- $\mu$ m carboxen/polydimethylsiloxane (CAR/PDMS) (stable flex) solid-phase microextraction (SPME) fibers were purchased from Supelco (Bellefonte, PA, USA).

\subsection{Study Protocol}

A randomized, placebo-controlled, single-center clinical trial with nutritional intervention was performed. The full details of the study protocol, inclusion/exclusion criteria, and a CONSORT chart are available elsewhere [42]. The present study is part of a larger study which was registered in the US National Library of Medicine (identifier: NCT03064997; http:/ / www.clinicaltrials.gov). The study was performed in the Gastrointestinal Clinic of the Children's Hospital in Olsztyn from January to June 2016. A brief description of original study is as follows: 34 children diagnosed with CD and following a GFD for at least six months were randomly assigned to a group receiving $10 \mathrm{~g}$ per day of oligofructose-enriched inulin (Synergy 1; Orafti ${ }^{\circledR}$, Beneo, Belgium) or a group receiving placebo (maltodextrin) for a period of 12 weeks. The placebo and prebiotic supplements were identical in appearance and taste. Participants and their caregivers, clinicians, and most of the investigators (except 
one person providing supplements) were blinded. During the intervention, participants were asked to note any side effects and daily supplement intake. Children were under the medical supervision of a gastroenterologist, and blood morphology data can be found elsewhere [43].

The study protocol was approved by the Bioethics Committee of the Faculty of Medicine of the University of Warmia and Mazury in Olsztyn, Poland (decision No. 23/2015). All procedures involving human participants were performed with the ethical principles of the 1964 Declaration of Helsinki and its later amendments. Parents or caregivers of participants were fully informed about the study and signed the written informed consent on the first check-up visit.

In the present study, urine samples collected from 23 children were analyzed: 11 children from the Synergy 1 group and 12 children from the placebo group. Patients' anthropometric characteristics are presented in Table 2. A smaller number of samples used in this study compared to the original study were related to antibiotic intake during the intervention (two persons), inappropriate compliance (less than $80 \%$ of time) to a nutritional intervention assessed based on the intervention diary (two persons), and insufficient amount of urine provided for VOC analysis (seven persons). Fresh morning urine samples were collected from each participant at baseline and after the intervention. Samples were immediately centrifuged at $3500 \mathrm{rpm}$ for $10 \mathrm{~min}$, and aliquots of $4 \mathrm{~mL}$ were stored at $-80{ }^{\circ} \mathrm{C}$ until further analysis.

Table 2. The participants' anthropometric data. Results are presented as ranges and means \pm standard deviation.

\begin{tabular}{cccc}
\hline & Synergy 1 Group & Placebo Group & $p$-Value \\
\hline$N$ & 11 & 12 & 0.886 \\
Gender & Girls-7; Boys-4 & Girls-8; Boys-4 & 0.720 \\
Age (years) & $5-18 ; \mathrm{Av}^{1}=10.8 \pm 4.1$ & $4-16 ; \mathrm{Av}=10.2 \pm 4.4$ & 0.703 \\
Body weight $(\mathrm{kg})$ & $15.8-67.9 ; \mathrm{Av}=38.3 \pm 16.9$ & $16.3-66.8 ; \mathrm{Av}=35.6 \pm 17.0$ & 0.540 \\
Height $(\mathrm{m})$ & $112.5-170.0 ; \mathrm{Av}=145.1 \pm 21.3$ & $103.0-172.0 ; \mathrm{Av}=139.4 \pm 22.6$ & 0.962 \\
BMI $\left(\mathrm{kg} / \mathrm{m}^{2}\right)$ & $12.5-23.5 ; \mathrm{Av}=17.2 \pm 3.7$ & $13.7-28.4 ; \mathrm{Av}=17.3 \pm 4.0$ &
\end{tabular}

\subsection{VOC Analysis}

Analysis of VOCs in urine was performed according to the previously published protocol [33]. Briefly, $4 \mathrm{~mL}$ of urine was placed in $20-\mathrm{mL}$ headspace vials with $2.98 \mathrm{~g}$ of sodium chloride and $21 \mu \mathrm{L}$ of $6 \mathrm{M}$ hydrochloric acid. Then, 4-methylpentan-2-ol was added to each sample as an internal standard with a concentration of $196.24 \mathrm{nmol} / \mathrm{L}$. Samples were incubated for $20 \mathrm{~min}$ at $30{ }^{\circ} \mathrm{C}$ with a shaking speed of $500 \mathrm{rpm}$ using a MultiTherm shaker (Benchmark Scientific, Edison, NJ, USA), resulting in the release of VOCs from urine and their accumulation at the headspace. Next, the previously conditioned CAR/PDMS fiber was manually inserted into the headspace, and extraction was carried out for $15 \mathrm{~min}$ at $30^{\circ} \mathrm{C}$. After extraction, the fiber was introduced into the gas chromatography injector port with a 0.75-mm inner diameter (ID) splitless glass liner (Supelco, Bellefonte, PA, USA), set to a splitless mode, with an inlet temperature of $240^{\circ} \mathrm{C}$. Thermal desorption was carried out for $10 \mathrm{~min}$ to avoid carryover.

Analysis of VOCs was performed using an HP 5890 gas chromatograph coupled with an HP 5972 mass selective detector (Agilent Technologies, Santa Clara, CA, USA) [33]. The compounds were separated using a Zebron ZB-624 capillary column, $60 \mathrm{~m} \times 0.25 \mathrm{~mm} \times 1.40 \mu \mathrm{m}$ (Phenomenex, Torrance, CA, USA). The carrier gas was helium at a constant flow rate of $1 \mathrm{~mL} \cdot \mathrm{min}^{-1}$. The oven temperature program was set as follows: $40{ }^{\circ} \mathrm{C}$ for $2 \mathrm{~min}$, an increase to $220{ }^{\circ} \mathrm{C}$ at a rate of $5{ }^{\circ} \mathrm{C} \cdot \mathrm{min}^{-1}$, and maintained at the final temperature for $5 \mathrm{~min}$. Total run time was $42 \mathrm{~min}$. Mass spectra were obtained by electron ionization (EI) in the range of $40-550 \mathrm{~m} / \mathrm{z}$, and a solvent delay was set for $5 \mathrm{~min}$. Ion source temperature was $230{ }^{\circ} \mathrm{C}$ and electronic impact energy was $70 \mathrm{eV}$. Total ion chromatograms were analyzed with the MSD ChemStation E.02.02.1431 software (Agilent Technologies, Santa Clara, CA, USA). Identification of compounds was performed by comparison of the retention times and mass spectra to commercial standards. Quantification of compounds was done by external 
standard calibration, and the results were normalized relative to the peak area of the internal standard. The previously described method was extended for analysis of acetone, pentan-2-one, D-limonene, and linalool. The content of pentan-2-one was calculated, using heptan-2-one as the external standard, by applying the arbitrary response factor of 1.00 . For all compounds, the calibration curves were prepared in the same way as described previously [33].

\subsection{Statistical Analysis}

All analyses were performed in duplicate. The normality of the quantitative variables was evaluated using the Shapiro-Wilk $W$ test. The comparison of anthropometric indices at baseline between Synergy 1 and the placebo group was performed using a parametric Student's $t$-test. As the VOC data showed non-normal distribution, quantitative variables were expressed as median values (P25-P75). Differences in the concentration of individual VOCs between Synergy 1 and the placebo group were tested with the non-parametric Mann-Whitney $U$ test. VOC concentrations within the group, before and after the intervention, were compared using the Wilcoxon signed-rank test. Results were considered statistically significant at the $5 \%$ critical level $(p<0.05)$. Exploratory data analysis using PCA was carried out to interpret the complex data and to determine if the differences between experimental groups could be seen. Both univariate and multivariate analyses were performed using XLSTAT for Excel software.

\section{Conclusions}

In summary, this pilot study indicated that oligofructose-enriched inulin, applied as a supplement of GFD for 12 weeks, had a moderate impact on the concentrations of VOCs in the headspace above the urine of children and adolescents with $\mathrm{CD}$. It is possible that the prolongation of the study may result in a more dominant effect. Further studies are needed to confirm the effect of prebiotics on gut integrity and, consequently, on the profile of VOCs in different biological fluids. Moreover, the origin of the VOCs in the human body requires further examination.

Author Contributions: N.D. conceived and designed the study presented here; U.K.-K. conceived the original clinical trial; N.D., E.J.-C., and U.K.-K. designed the original study; N.D. and E.J.-C. collected samples; N.D. performed all experiments, was responsible for methodology, analyzed and interpreted the data, prepared visualization of data, acquired funding, and administrated the PRELUDIUM Project; N.D., E.J.-C., and U.K.-K. provided resources; N.D. wrote the manuscript; N.M.R. helped in the interpretation of the data and critically revised the manuscript; all authors reviewed and approved the final version of the manuscript.

Funding: This research was funded by the Polish National Science Centre through project PRELUDIUM 11 (project number: 2016/21/N/NZ9/01510).

Acknowledgments: We wish to sincerely thank all patients who participated in this study. The samples were collected in the study supported by statutory funds of the Department of Chemistry and Biodynamics of Food of the Institute of Animal Reproduction and Food Research, Polish Academy of Science (GW20).

Conflicts of Interest: The authors declare no conflict of interest.

\section{References}

1. Probert, C.S.J.; Ahmed, I.; Khalid, T.; Johnson, E.; Smith, S.; Ratcliffe, N. Volatile Organic Compounds as Diagnostic Biomarkers in Gastrointestinal and Liver Diseases. J. Gastrointest. Liver Dis. 2009, 18, 337-343.

2. Buljubasic, F.; Buchbauer, G. The scent of human diseases: A review on specific volatile organic compounds as diagnostic biomarkers. Flavour Fragr. J. 2015, 30, 5-25. [CrossRef]

3. Garner, C.E.; Smith, S.; de Lacy Costello, B.; White, P.; Spencer, R.; Probert, C.S.J.; Ratcliffe, N.M. Volatile organic compounds from feces and their potential for diagnosis of gastrointestinal disease. FASEB J. 2007, 21, 1675-1688. [CrossRef] [PubMed]

4. Di Cagno, R.; De Angelis, M.; De Pasquale, I.; Ndagijimana, M.; Vernocchi, P.; Ricciuti, P.; Gagliardi, F.; Laghi, L.; Crecchio, C.; Guerzoni, M.; et al. Duodenal and faecal microbiota of celiac children: Molecular, phenotype and metabolome characterization. BMC Microbiol. 2011, 11, 219. [CrossRef] [PubMed] 
5. Arasaradnam, R.P.; Ouaret, N.; Thomas, M.G.; Quraishi, N.; Heatherington, E.; Nwokolo, C.U.; Bardhan, K.D.; Covington, J.A. A novel tool for noninvasive diagnosis and tracking of patients with inflammatory bowel disease. Inflamm. Bowel Dis. 2013, 19, 999-1003. [CrossRef] [PubMed]

6. Arasaradnam, R.P.; Westenbrink, E.; McFarlane, M.J.; Harbord, R.; Chambers, S.; O'Connell, N.; Bailey, C.; Nwokolo, C.U.; Bardhan, K.D.; Savage, R.; et al. Differentiating coeliac disease from irritable bowel syndrome by urinary volatile organic compound analysis-A pilot study. PLoS ONE 2014, 9, e107312. [CrossRef] [PubMed]

7. McGuire, N.D.; Ewen, R.J.; De Lacy Costello, B.; Garner, C.E.; Probert, C.S.J.; Vaughan, K.; Ratcliffe, N.M. Towards point of care testing for $\mathrm{C}$. difficile infection by volatile profiling, using the combination of a short multi-capillary gas chromatography column with metal oxide sensor detection. Meas. Sci. Technol. $2014,25$. [CrossRef] [PubMed]

8. Ahmed, I.; Greenwood, R.; de Costello, B.L.; Ratcliffe, N.M.; Probert, C.S. An Investigation of Fecal Volatile Organic Metabolites in Irritable Bowel Syndrome. PLoS ONE 2013, 8, e58204. [CrossRef]

9. Cauchi, M.; Fowler, D.P.; Walton, C.; Turner, C.; Jia, W.; Whitehead, R.N.; Griffiths, L.; Dawson, C.; Bai, H.; Waring, R.H.; et al. Application of gas chromatography mass spectrometry (GC-MS) in conjunction with multivariate classification for the diagnosis of gastrointestinal diseases. Metabolomics 2014, 10, 1113-1120. [CrossRef]

10. Aprea, E.; Cappellin, L.; Gasperi, F.; Morisco, F.; Lembo, V.; Rispo, A.; Tortora, R.; Vitaglione, P.; Caporaso, N.; Biasioli, F. Application of PTR-TOF-MS to investigate metabolites in exhaled breath of patients affected by coeliac disease under gluten free diet. J. Chromatogr. B Anal. Technol. Biomed. Life Sci. 2014, 966, 208-213. [CrossRef] [PubMed]

11. Baranska, A.; Tigchelaar, E.; Smolinska, A.; Dallinga, J.W.; Moonen, E.J.C.; Dekens, J.A.M.; Wijmenga, C.; Zhernakova, A.; Van Schooten, F.J. Profile of volatile organic compounds in exhaled breath changes as a result of gluten-free diet. J. Breath Res. 2013, 7, 037104. [CrossRef]

12. Hicks, L.C.; Huang, J.; Kumar, S.; Powles, S.T.; Orchard, T.R.; Hanna, G.B.; Williams, H.R.T. Analysis of Exhaled Breath Volatile Organic Compounds in Inflammatory Bowel Disease: A Pilot Study. J. Crohns. Colitis 2015, 9, 731-737. [CrossRef]

13. Broza, Y.Y.; Mochalski, P.; Ruzsanyi, V.; Amann, A.; Haick, H. Hybrid Volatolomics and Disease Detection. Angew. Chemie Int. Ed. 2015, 54, 11036-11048. [CrossRef] [PubMed]

14. Rossi, M.; Aggio, R.; Staudacher, H.M.; Lomer, M.C.; Lindsay, J.O.; Irving, P.; Probert, C.; Whelan, K. Volatile Organic Compounds in Feces Associate With Response to Dietary Intervention in Patients With Irritable Bowel Syndrome. Clin. Gastroenterol. Hepatol. 2018, 16, 385-391. [CrossRef]

15. Wu, G.D.; Compher, C.; Chen, E.Z.; Smith, S.A.; Shah, R.D.; Bittinger, K.; Chehoud, C.; Albenberg, L.G.; Nessel, L.; Gilroy, E.; et al. Comparative metabolomics in vegans and omnivores reveal constraints on diet-dependent gut microbiota metabolite production. Gut 2016, 65, 63-72. [CrossRef] [PubMed]

16. Beaumont, M.; Portune, K.J.; Steuer, N.; Lan, A.; Cerrudo, V.; Audebert, M.; Dumont, F.; Mancano, G.; Khodorova, N.; Andriamihaja, M.; et al. Quantity and source of dietary protein influence metabolite production by gut microbiota and rectal mucosa gene expression: A randomized, parallel, double-blind trial in overweight humans. Am. J. Clin. Nutr. 2017, 106, 1005-1019. [CrossRef] [PubMed]

17. Drabińska, N.; Jarocka-Cyrta, E.; Markiewicz, L.H.; Krupa-Kozak, U. The Effect of Oligofructose-Enriched Inulin on Faecal Bacterial Counts and Microbiota-Associated Characteristics in Celiac Disease Children Following a Gluten-Free Diet: Results of a Randomized, Placebo-Controlled Trial. Nutrients 2018, 10, 201. [CrossRef] [PubMed]

18. De Lacy Costello, B.; Amann, A.; Al-Kateb, H.; Flynn, C.; Filipiak, W.; Khalid, T.; Osborne, D.; Ratcliffe, N.M. A review of the volatiles from the healthy human body. J. Breath Res. 2014, 8, 014001. [CrossRef] [PubMed]

19. Bischoff, S.C.; Barbara, G.; Buurman, W.; Ockhuizen, T.; Schulzke, J.D.; Serino, M.; Tilg, H.; Watson, A.; Wells, J.M. Intestinal permeability-A new target for disease prevention and therapy. BMC Gastroenterol. 2014, 14, 189. [CrossRef] [PubMed]

20. Heyman, M.; Abed, J.; Lebreton, C.; Cerf-Bensussan, N. Intestinal permeability in coeliac disease: Insight into mechanisms and relevance to pathogenesis. Gut 2012, 61, 1355-1364. [CrossRef]

21. Mills, G.A.; Walker, V. Headspace solid-phase microextraction profiling of volatile compounds in urine: Application to metabolic investigations. J. Chromatogr. B Biomed. Sci. Appl. 2001, 753, 259-268. [CrossRef] 
22. Benkebil, F.; Combescure, C.; Anghel, S.I.; Besson Duvanel, C.; Schäppi, M.G. Diagnostic accuracy of a new point-of-care screening assay for celiac disease. World J. Gastroenterol. 2013, 19, 5111-5117. [CrossRef] [PubMed]

23. Nistal, E.; Caminero, A.; Vivas, S.; Ruiz De Morales, J.M.; Sáenz De Miera, L.E.; Rodríguez-Aparicio, L.B.; Casqueiro, J. Differences in faecal bacteria populations and faecal bacteria metabolism in healthy adults and celiac disease patients. Biochimie 2012, 94, 1724-1729. [CrossRef] [PubMed]

24. Galli, G.; Esposito, G.; Lahner, E.; Pilozzi, E.; Corleto, V.D.; Di Giulio, E.; Aloe Spiriti, M.A.; Annibale, B. Histological recovery and gluten-free diet adherence: A prospective 1-year follow-up study of adult patients with coeliac disease. Aliment. Pharmacol. Ther. 2014, 40, 639-647. [CrossRef] [PubMed]

25. Bardella, M.T.; Velio, P.; Cesana, B.M.; Prampolini, L.; Casella, G.; Di Bella, C.; Lanzini, A.; Gambarotti, M.; Bassotti, G.; Villanacci, V. Coeliac disease: A histological follow-up study. Histopathology 2007, 50, 465-471. [CrossRef] [PubMed]

26. Vici, G.; Belli, L.; Biondi, M.; Polzonetti, V. Gluten free diet and nutrient deficiencies: A review. Clin. Nutr. 2016, 35, 1236-1241. [CrossRef]

27. Gibson, G.R.; Hutkins, R.; Sanders, M.E.; Prescott, S.L.; Reimer, R.A.; Salminen, S.J.; Scott, K.; Stanton, C.; Swanson, K.S.; Cani, P.D.; et al. Expert consensus document: The International Scientific Association for Probiotics and Prebiotics (ISAPP) consensus statement on the definition and scope of prebiotics. Nat. Rev. Gastroenterol. Hepatol. 2017, 14, 491-502. [CrossRef]

28. Holloway, L.; Moynihan, S.; Abrams, S.A.; Kent, K.; Hsu, A.R.; Friedlander, A.L. Effects of oligofructoseenriched inulin on intestinal absorption of calcium and magnesium and bone turnover markers in postmenopausal women. Br. J. Nutr. 2007, 97, 365-372. [CrossRef]

29. Liu, T.-W.; Cephas, K.D.; Holscher, H.D.; Kerr, K.R.; Mangian, H.F.; Tappenden, K.A.; Swanson, K.S. Nondigestible Fructans Alter Gastrointestinal Barrier Function, Gene Expression, Histomorphology, and the Microbiota Profiles of Diet-Induced Obese C57BL/6J Mice. J. Nutr. 2016, 146, 949-956. [CrossRef] [PubMed]

30. Drabińska, N.; Krupa-Kozak, U.; Ciska, E.; Jarocka-Cyrta, E. Plasma profile and urine excretion of amino acids in children with celiac disease on gluten-free diet after oligofructose-enriched inulin intervention: Results of a randomised placebo-controlled pilot study. Amino Acids 2018, 50, 1451-1460. [CrossRef]

31. Drabińska, N.; Krupa-Kozak, U.; Abramowicz, P.; Jarocka-Cyrta, E. Beneficial Effect of OligofructoseEnriched Inulin on Vitamin D and E Status in Children with Celiac Disease on a Long-Term Gluten-Free Diet: A Preliminary Randomized, Placebo-Controlled Nutritional Intervention Study. Nutrients 2018, 10, 1768. [CrossRef]

32. Drabińska, N.; Jarocka-Cyrta, E.; Złotkowska, D.; Abramowicz, P.; Krupa-Kozak, U. Daily oligofructoseenriched inulin intake impacts bone turnover markers but not the cytokine profile in paediatric patients with coeliac disease on a gluten-free diet: Results of a randomised, placebo-controlled pilot study. Bone 2019, 122, 184-192. [CrossRef] [PubMed]

33. Drabińska, N.; Azeem, H.A.; Krupa-Kozak, U. A targeted metabolomic protocol for quantitative analysis of volatile organic compounds in urine of children with celiac disease. RSC Adv. 2018, 8, 36534-36541. [CrossRef]

34. Nierop Groot, M.N.; De Bont, J.A.M. Conversion of phenylalanine to benzaldehyde initiated by an aminotransferase in Lactobacillus plantarum. Appl. Environ. Microbiol. 1998, 64, 3009-3013. [PubMed]

35. Jeon, D.H.; Park, G.Y.; Kwak, I.S.; Lee, K.H.; Park, H.J. Antioxidants and their migration into food simulants on irradiated LLDPE film. LWT Food Sci. Technol. 2007, 40, 151-156. [CrossRef]

36. Duerksen, D.R.; Wilhelm-Boyles, C.; Parry, D.M. Intestinal permeability in long-term follow-up of patients with celiac disease on a gluten-free diet. Dig. Dis. Sci. 2005, 50, 785-790. [CrossRef] [PubMed]

37. Russo, F.; Linsalata, M.; Clemente, C.; Chiloiro, M.; Orlando, A.; Marconi, E.; Chimienti, G.; Riezzo, G. Inulin-enriched pasta improves intestinal permeability and modifies the circulating levels of zonulin and glucagon-like peptide 2 in healthy young volunteers. Nutr. Res. 2012, 32, 940-946. [CrossRef] [PubMed]

38. Westerbeek, E.A.M.; Van Den Berg, A.; Lafeber, H.N.; Fetter, W.P.F.; Van Elburg, R.M. The effect of enteral supplementation of a prebiotic mixture of non-human milk galacto-, fructo- and acidic oligosaccharides on intestinal permeability in preterm infants. Br. J. Nutr. 2011, 105, 268-274. [CrossRef] [PubMed]

39. Wilms, E.; Gerritsen, J.; Smidt, H.; Besseling-Van Der Van Vaart, I.; Rijkers, G.T.; Fuentes, A.R.G.; Masclee, A.A.M.; Troost, F.J. Effects of supplementation of the synbiotic Ecologic ${ }^{\circledR} 825 /$ FOS P6 on intestinal barrier function in healthy humans: A randomized controlled trial. PLoS ONE 2016, 11, e0167775. [CrossRef] 
40. Ten Bruggencate, S.J.M.; Bovee-Oudenhoven, I.M.J.; Lettink-Wissink, M.L.G.; Katan, M.B.; van der Meer, R. Dietary fructooligosaccharides affect intestinal barrier function in healthy men. J. Nutr. 2006, 136, 70-74. [CrossRef]

41. Krusinska, B.; Hawrysz, I.; Wadolowska, L.; Slowinska, M.A.; Biernacki, M.; Czerwinska, A.; Golota, J.J. Associations of mediterranean diet and a posteriori derived dietary patterns with breast and lung cancer risk: A case-control study. Nutrients 2018, 10. [CrossRef] [PubMed]

42. Krupa-Kozak, U.; Drabińska, N.; Jarocka-Cyrta, E. The effect of oligofructose-enriched inulin supplementation on gut microbiota, nutritional status and gastrointestinal symptoms in paediatric coeliac disease patients on a gluten-free diet: Study protocol for a pilot randomized controlled trial. Nutr. J. 2017, 16, 47. [CrossRef] [PubMed]

43. Feruś, K.; Drabińska, N.; Krupa-Kozak, U.; Jarocka-Cyrta, E. A Randomized, Placebo-Controlled, Pilot Clinical Trial to Evaluate the Effect of Supplementation with Prebiotic Synergy 1 on Iron Homeostasis in Children and Adolescents with Celiac Disease Treated with a Gluten-Free Diet. Nutrients 2018, 10, 1818. [CrossRef] [PubMed]

Sample Availability: Samples of the compounds are not available from the authors. 